\title{
Propolis and its Active Component, Caffeic Acid Phenethyl Ester (CAPE), Modulate Breast Cancer Therapeutic Targets via an Epigenetically Mediated Mechanism of Action
}

\section{Coral Omene ${ }^{1,5 *}$, Matko Kalac ${ }^{1,5}$, Jing Wu'2, Enrica Marchi ${ }^{1,3,4}$, Krystyna Frenkel ${ }^{2,5}$ and Owen A O'Connor ${ }^{1,3,4}$}

${ }^{1}$ Department of Medicine, NYU School of Medicine, New York, USA

${ }^{2}$ Department of Environmental Medicine, NYU School of Medicine, New York, USA

${ }^{3}$ Center for Lymphoid Malignancies, Columbia University Medical Center, New York, USA

${ }^{4}$ Herbert Irving Comprehensive Cancer Center, Columbia University, New York, USA

${ }^{5}$ NYU Cancer Institute, NYU School of Medicine, New York, USA

\begin{abstract}
Alternative remedies for cancer treatment is a multi-billion dollar industry. In particular, breast cancer (BC) patients use alternative and natural remedies more frequently than patients with other malignancies. Propolis is an example of a honeybee-produced naturopathic formulation, contents of which differ by geographic location. It is readily available, affordable, and in use safely since ancient times globally. Caffeic acid phenethyl ester (CAPE) is a major active component in propolis and is thought to be responsible for its varied properties, including antibacterial, antiviral, antifungal, antioxidant, anti-inflammatory and anticancer. CAPE is effective in many models of human cancer, including BC as we have previously shown. CAPE affects genes associated with tumor cell growth and survival, angiogenesis and chemoresistance. We demonstrate that these are related in part to CAPE's role as a histone deacetylase inhibitor, a class of drugs designated as epigenetic agents that modulate the activities of oncogenes and tumor suppressor genes. CAPE and propolis, cause an accumulation of acetylated histone proteins in MCF-7 (ER+) and MDA-MB-231 (ER-/PR-/Her2-) cells with associated decreases in ER and PR in MCF-7 cells, and upregulation of ER and decrease in EGFR in MDA-231 cells. In addition, these products reduced activated phosphorylated Her2 protein in SKBR3 $(\mathrm{Her} 2+)$ cells. Interestingly, propolis, when normalized for CAPE content, appears to be more potent than CAPE alone similarly to the greater effects of complete foods than isolated components. These data provide a potential mechanistic basis for one of the oldest naturopathic agents used in medicine and cancer treatment.
\end{abstract}

Keywords: Propolis; CAPE; Breast cancer; HDAC inhibitor

Abbreviations: CAPE: Caffeic Acid Phenethyl Ester; HDACi: Histone Deacetylase Inhibitor; TNBC: Triple-Negative Breast Cancer Cells; EGFR: Epidermal Growth Factor Receptor

\section{Introduction}

The use of alternative therapies for the treatment of cancer is rapidly growing in popularity in the U.S, amounting to a multi-billion dollar industry according to the Nutritional business journal (NBJ) Integrative Medicine Report in 2009. Up to $80 \%$ of cancer patients admit to using complementary or alternative medicine [1]. Often times, cancer patients use these supplements despite recommendations not to do so by their oncologists. Most oncologists strongly discourage the use of such agents because of the lack of evidence showing benefit, the absence of supportive scientific data, and the concern about possible drug: drug interactions. Breast cancer (BC) patients, in particular, favor the use of alternative and natural remedies, with as many as $63 \%-83 \%$ of $\mathrm{BC}$ patients admitting to the use of at least one type of alternative medicine, and 25\%-63\% admitting to the routine self-administration of herbal and vitamin remedies [2-5], despite medical advice.

Caffeic acid phenethyl ester (CAPE) is one of the main medicinal components of the natural product, propolis produced by American and European honeybees. Propolis is collected by honeybees from buds and exudates of conifer trees and plants and is known to contain a variety of chemical compounds such as flavonoids, phenolic acids, and their esters, terpenoids, steroids and assorted amino-acids [6]. Importantly, literature going back to ancient times, reveal that Propolis has been used as a natural remedy. Egyptians knew very well the antiputrefactive properties of propolis and used it to embalm cadavers.
Propolis was recognized for its multiplicity of medicinal uses, and remarkable safety profile by the Greek and Roman physicians, Aristoteles, Dioscorides, Pliny and Galen [7-9].

CAPE possesses a number of important biological activities, including anti-bacterial, anti-viral, anti-fungal, anti-oxidant, antiinflammatory, and anti-cancer properties [10-16]. CAPE has been shown to be cytotoxic to many types of cancer cells, including breast cancer cells, while having no such effects against normal cells [17-26]. We have previously demonstrated that CAPE: (i) inhibits the growth of MDA-MB-231 (MDA-231) triple-negative (ER-, PR-, Her2-) BC cells (TNBC), and MCF-7 (ER+/PR+) BC cells both in vivo and in vitro; (ii) inhibits growth of breast cancer stem cells; (iii) induces cell cycle arrest and apoptosis and (iv) suppresses angiogenesis $[25,26]$. These findings are reminiscent of the pleiotropic effects seen with drugs targeting the epigenetic apparatus such as the histone deacetylases inhibitors

*Corresponding author: Coral Omene, Department of Medicine, Division of Hematology/Oncology, NYU School of Medicine, 550 First Avenue, BCD, Rm 556 NY, NY, 10016, USA, Tel: 212-263-6485; Fax: 212-263-8210; E-mail coral.omene@nyumc.org, comene01@gmail.com

Received August 16, 2013; Accepted October 18, 2013; Published October 21 2013

Citation: Omene C, Kalac M, Wu J, Marchi E, Frenkel K, et al. (2013) Propolis and its Active Component, Caffeic Acid Phenethyl Ester (CAPE), Modulate Breast Cancer Therapeutic Targets via an Epigenetically Mediated Mechanism of Action. J Cancer Sci Ther 5: 334-342. doi:10.4172/1948-5956.1000224

Copyright: $\odot 2013$ Omene C, et al. This is an open-access article distributed under the terms of the Creative Commons Attribution License, which permits unrestricted use, distribution, and reproduction in any medium, provided the original author and source are credited. 
Citation: Omene C, Kalac M, Wu J, Marchi E, Frenkel K, et al. (2013) Propolis and its Active Component, Caffeic Acid Phenethyl Ester (CAPE), Modulate Breast Cancer Therapeutic Targets via an Epigenetically Mediated Mechanism of Action. J Cancer Sci Ther 5: 334-342. doi:10.4172/1948-5956.1000224

(HDACi) like vorinostat, aliphatic acids and depsipeptide in models of both epithelial and hematopoietic origin. Epigenetic mechanisms, such as histone modification, regulate specific gene expression patterns that are essential for normal development. This process can change the accessibility of transcription factors to chromatin as well as recruit co-activators or repressors to targeted genes, thereby modulating gene expression $[27,28]$. HDAC inhibitors have been shown to have antitumor effects, especially in lymphoid malignancies where Vorinostat and romidepsin have been approved for the treatment of patients with relapsed or refractory cutaneous and peripheral T-cell lymphomas [2931].

In this study, we hypothesized that CAPE, which is structurally similar to the hydroxamic acid class of HDAC inhibitors, may mediate its effects on breast cancer through epigenetic modifications and investigated its effects on histone proteins, as well as those therapeutic targets shown to be modulated by other HDAC inhibitors in models of breast cancer, including ER, PR, Her2 neu, and epidermal growth factor receptor (EGFR).

\section{Materials and Methods}

\section{Cell culture}

MDA-MB-231, MCF-7, and SKBR3 were purchased from the American Type Culture Collection (ATCC, Manassas, VA), and used for in vitro experiments. Cells were cultured in DMEM (Cellgro, Manassas, VA) supplemented with 10\% heat-inactivated FBS (Cellgro, Manassas, VA) at $37^{\circ} \mathrm{C}$ in a humidified $5 \% \mathrm{CO}_{2}$ incubator. All cells were passaged twice a week and maintained in exponential growth.

\section{Cytotoxicity or cell viability}

Cells were counted at $3 \times 10^{5}$ cells $/ \mathrm{mL}$ in a 48 well plate (BD Labware, Franklin Lakes, NJ). CAPE (Sigma, Aldrich) was used at the concentrations of 0 to $80 \mu \mathrm{M}$ and propolis ethanolic extract (eBee Honey, Ashland, $\mathrm{OH}$ ) was diluted with ethanol to obtain concentrations from $0 \%$ to $0.5 \%$. Following incubation at $37^{\circ} \mathrm{C}$ in a $5 \% \mathrm{CO}_{2}$ humidified incubator, $100 \mu \mathrm{Lfrom}$ each well was transferred to a 96-well opaquewalled plate. Cell-Titer-Glo Reagent (Promega Corporation, Madison,
WI) was added in 1:1 ratio. Contents were mixed for 2 mins on an orbital shaker to induce cell lysis then left to incubate at room temperature for 10 mins before recording luminescence with the Synergy HT MultiDetection Microplate Reader (Biotek Instruments, Inc., Winooski, VT). Each experiment was performed in triplicate.

\section{Western blotting}

Cells were seeded and cultured for $12 \mathrm{~h}$ and then treated with CAPE or propolis for $24 \mathrm{~h}$. Alternatively, PBMC from a healthy volunteer was collected after a 3 week oral ingestion of CAPE-containing propolis Whole cell protein lysates were prepared according to standard protocol using RIPA buffer ( $1 \mathrm{M}$ Tris- $\mathrm{HCl}, \mathrm{pH} 8,2.5 \mathrm{M} \mathrm{NaCl}, 5 \%$ deoxycholic acid, 100\% NP-40, 20\%SDS) with protease and phosphatase inhibitors added. After protein quantification according to Bradford's method, electrophoresis was performed on $4-20 \%$ gradient SDS-PAGE gels. Proteins were transferred to nitrocellulose membranes and the quality of the proteins was checked with Ponceau. Membranes were blocked in TBS-T ( $0.1 \%$ Tween 20$)$ with $5 \%$ non-fat dry milk, incubated overnight with the primary antibody (1:250), and then incubated with a secondary peroxidase-linked antibody (1:5000). Detection was performed using enhanced chemoluminescence system (Amersham Biosciences) and the X-ray films were exposed to the membranes. Anti- $\beta$-actin antibody was used to ensure equal loading of protein onto the gel. The following primary antibodies were used: antibodies to EGFR, p-Her2, ER- $\alpha$, and PR were obtained from (Santa Cruz Biotechnology, Santa Cruz, CA) and used at a ratio 1:250 dilution, acetyl-histone H3 (Lys9) antibody (Catalog \# 9671, Cell Signaling Technology, Boston, MA) and anti- $\beta$ actin (Cell Signaling Technology, Boston, MA). Goat anti-rabbit (Santa Cruz Biotechnology, Santa Cruz, CA) secondary antibody was used. LBH 589 (HDACi control, Panobinostat) was obtained from Novartis Pharmaceuticals, Inc. (Cambridge, Massachussets) and used at a concentration of $100 \mathrm{nM}$ as a positive control. Each experiment was performed at least three times (Figure 1).

\section{Immunofluorescence}

$3 \times 10^{4}$ cells were seeded and cultured for $12 \mathrm{~h}$ and then cultured and treated with or without CAPE or propolis for $24 \mathrm{~h}$ or with LBH

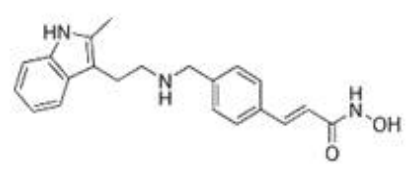

LBH 589 (Panobinostat) $\mathrm{C}_{21} \mathrm{H}_{23} \mathrm{~N}_{3} \mathrm{O}_{2}$

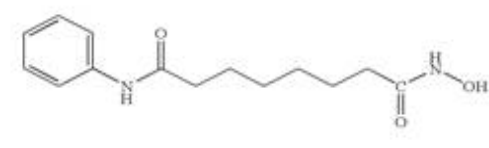

suberoylanilide hydroxamic acid (SAHA)

$\mathrm{C}_{14} \mathrm{H}_{20} \mathrm{~N}_{2} \mathrm{O}_{3}$<smiles>O=C(/C=C/c1ccc(O)c(O)c1)OCCc1ccccc1</smiles>

Caffeic Acid Phenethyl Ester (CAPE) $\mathrm{C}_{17} \mathrm{H}_{16} \mathrm{O}_{4}$

Figure 1: Structural similarity between CAPE and established HDAC inhibitors. 
Citation: Omene C, Kalac M, Wu J, Marchi E, Frenkel K, et al. (2013) Propolis and its Active Component, Caffeic Acid Phenethyl Ester (CAPE), Modulate Breast Cancer Therapeutic Targets via an Epigenetically Mediated Mechanism of Action. J Cancer Sci Ther 5: 334-342. doi:10.4172/1948-5956.1000224

589 (HDACi control) in 96-well plates. Cells were washed with $1 \mathrm{x}$ PBS and fixed in $4 \%$ formaldehyde at room temperature for 20 mins. Permeabilization and blocking was carried out in 1X PBST containing $2 \% \mathrm{BSA} / 0.1 \%$ Triton $\mathrm{X}$ at room temperature for 20 mins. Cells were then incubated with a primary antibody, i.e., anti-ER- $\alpha(1: 50)$ and incubated at $4 \mathrm{C}$ overnight. After 24 hours, cells were washed, incubated with a secondary antibody (1:1000) and DAPI (1:1000) in the dark for $1 \mathrm{~h}$. Cells were washed 3 times prior to imaging. The images were collected using Nikon Eclipse TE 2000-E inverted epifluorescent microscope, a 40x/0.60 oil objective and a Nikon Photometrics Coolsnap HQ2 camera. The images were analyzed using NIS-elements AR 3.2 software and Volocity 5.5.1 software. Each experiment was performed in triplicate.

\section{RT PCR}

$3 \times 10^{5}$ cells were seeded, cultured in phenol red-free DMEM containing charcoal stripped FBS (Cellgro, Manassas, VA)in six-well tissue culture plates in $3 \mathrm{ml}$ media in the absence or presence of CAPE or propolis or with LBH $589(200 \mathrm{nM})$ for $48 \mathrm{~h}$. Total RNA from each treated population was extracted by mini RNeasy kit (Qiagen). Reverse transcription (RT) of total RNA to cDNA was carried out according to the instructions provided (Invitrogen) using the following estrogen receptor primer: ER sense (S): GCA CCC TGA AGT CTC TGG AA; antisense (AS): TGG CTA AAG TGG TGC ATG AT. The resultant cDNA was amplified by PCR to determine expression of the estrogen receptor with $\beta$-actin used as a control. PCR was carried out in a Thermal Cycler (Labnet International Inc.). After initial denaturation at $95^{\circ} \mathrm{C}$ for $15 \mathrm{~min}, \mathrm{PCR}$ was carried out as follows: denaturation at $94^{\circ} \mathrm{C}$ for $0.5 \mathrm{~min}$, annealing at $58^{\circ} \mathrm{C}$ for $1 \mathrm{~min}$, and extension at $72^{\circ} \mathrm{C}$ for $10 \mathrm{~min}$, for a total of 34 cycles. PCR products were separated on
$1 \%$ agarose gel containing ethydium bromide and visualized under UV light.

\section{Results}

\section{Cytotoxicity of CAPE and propolis}

The cytotoxic effects of various concentrations of CAPE and propolis (normalized for CAPE content by High Performance Liquid Chromatography [HPLC]) on breast cancer cells are shown in Figure 2. The viability of MCF-7 (ER+), MDA-231 (ER-/PR-/Her2-, TNBC), and SKBR3 (Her2+) breast cancer cells was decreased in a concentration and time-dependent manner by CAPE at all time points tested (Figure $2 \mathrm{~A})$ with an $\mathrm{IC}_{50}$ of $20 \mu \mathrm{M}$ (MCF-7, SKBR3) and $35 \mu \mathrm{M}$ (MDA-231) at $72 \mathrm{~h}$. This decrease in viability was even more potent when using propolis. Propolis exhibited enhanced cytotoxicity at all the time points tested with an $\mathrm{IC}_{50}$ of about $10 \mu \mathrm{M}$ for all the cell lines at $72 \mathrm{~h}$ (Figure 2B).

\section{Acetylation of histone (H3)}

Cells were treated with or without CAPE or propolis for 24 $\mathrm{h}$ and lysates immunoblotted for acetylated histones in Figure 3. Concentration dependent acetylation of histone proteins was observed for both CAPE and propolis in the MDA-231 and MCF-7 cell lines (Figure 3A). The accumulation of acetylated histones as depicted by Western blotting was observed at a much lower dose of CAPE when propolis was used, up to 10 -fold lower. A similar observation of hyper-acetylated histone proteins was observed in peripheral blood mononuclear cells (PBMC) from a healthy human volunteer after a 3-week oral ingestion of CAPE-containing propolis (Figure 3B).

A.

\section{CAPE}

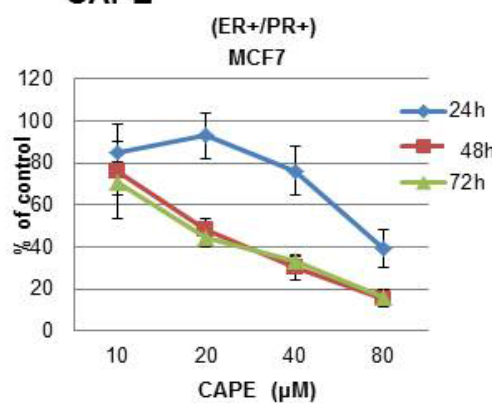

B.

\section{Propolis*}

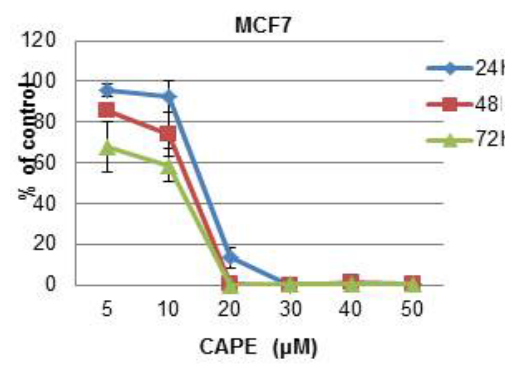

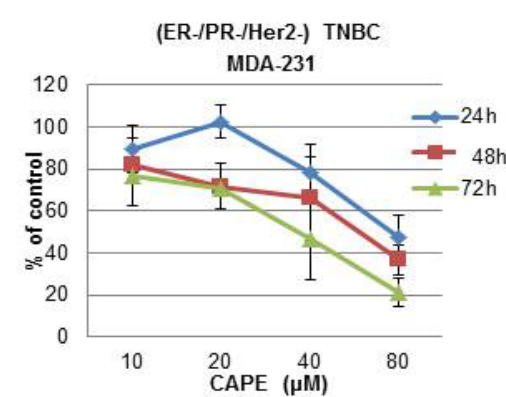

MDA-231

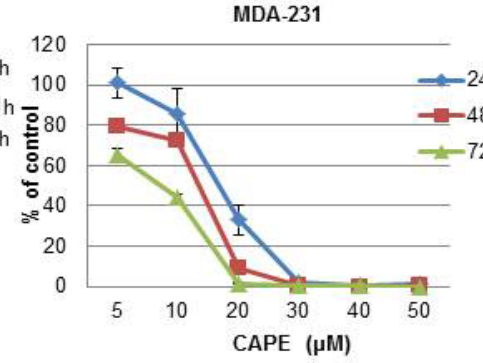

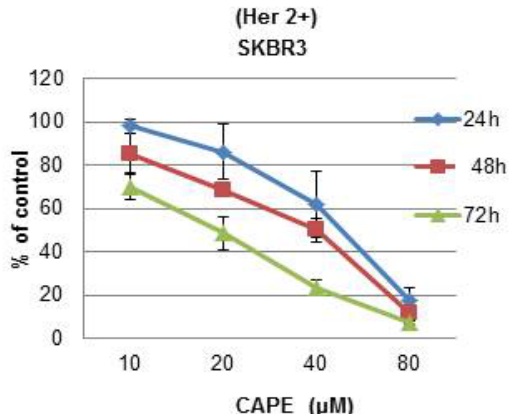

CAPE $(\mu M)$

Figure 2: A, B: Propolis/CAPE are cytotoxic to breast cancer cells: Cells were treated with CAPE or propolis for $24 \mathrm{~h}, 48 \mathrm{~h}$ and $72 \mathrm{~h}$. CAPE and propolis (normalized for CAPE content by Human Plasma Liquid Chromatography (HPLC) exposure results in decreased viability of MDA-231 (ER-/PR-/Her2-, TNBC), MCF-7 (ER+) and SKBR3 (Her2 +) breast cancercells in a time-dependent and concentration-dependent manner. 
Citation: Omene C, Kalac M, Wu J, Marchi E, Frenkel K, et al. (2013) Propolis and its Active Component, Caffeic Acid Phenethyl Ester (CAPE), Modulate Breast Cancer Therapeutic Targets via an Epigenetically Mediated Mechanism of Action. J Cancer Sci Ther 5: 334-342. doi:10.4172/1948-5956.1000224

A.

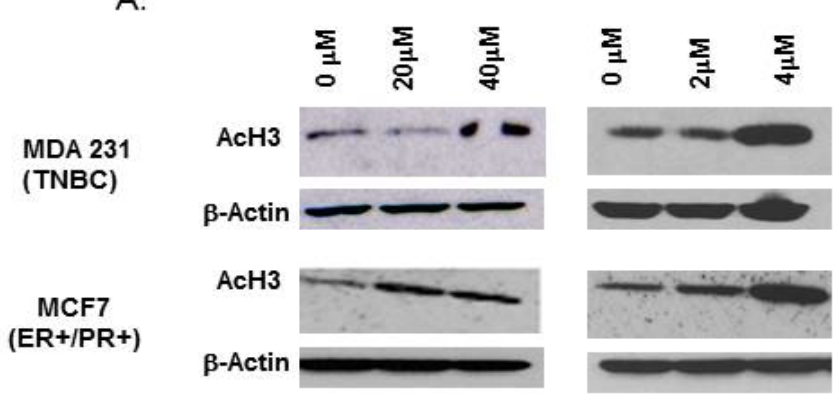

B.

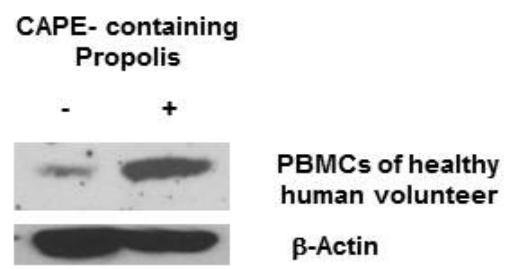

Figure 3: Propolis/CAPE is an HDAC inhibitor and induces hyperacetylation of histone proteins: Protein lysates were obtained from cells were treated with CAPE or propolis for $24 \mathrm{~h}$, or from PBMC from a healthy volunteer after a 3 week oral ingestion of CAPE-containing propolis. Western Blotting was performed for acetylated histone H3. Hyperacetylation of histone proteins is induced in a concentration-dependent manner by both CAPE and propolis (normalized for CAPE content) in MCF-7 and MDA-231 cells (Figure $3 \mathrm{~A}$ ) and in peripheral blood mononuclear cells from a healthy human volunteer after oral ingestion of CAPE-containing propolis (Figure 3B).

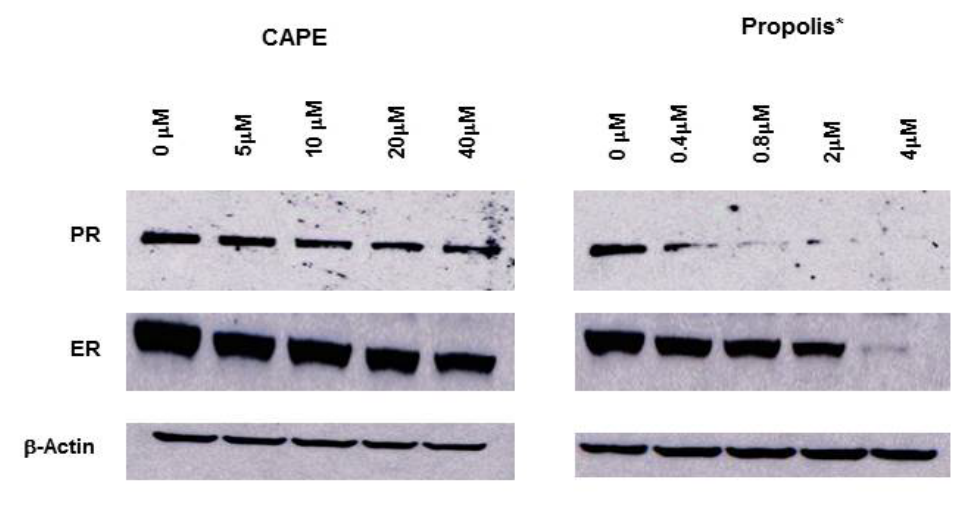

MCF-7 (ER+/PR+)

Figure 4: Propolis/CAPE decrease ER- $\alpha$ and PR expression in MCF-7 cells: MCF-7 cells were treated with CAPE or propolis for $24 \mathrm{~h}$ and Western blotting performed. ER- $\alpha$ and PR expression decreases in a concentration-dependent manner after exposure with CAPE or propolis (normalized for CAPE content).

\section{Epigenetic effects on ER- $\alpha$ and PR expression in MCF-7 cells}

MCF-7 cells were treated with CAPE or propolis for $24 \mathrm{~h}$ and lysates were immunoblotted to test for ER- $\alpha$ and PR. There was a concentration dependent decrease in the expression of ER- $\alpha$ and PR after treatment with CAPE or propolis (Figure 4). Similarly to the previous observations shown in Figure 2 and 3, propolis, normalized for CAPE content, was more potent than CAPE in reducing the amount of the PR receptor to near undetectable levels at $0.4 \mu \mathrm{M}$. ER- $\alpha$ was also decreased by CAPE and propolis, but again the inhibitory effect on ER- $\alpha$ was more pronounced with propolis, when normalized for CAPE content, where ER was undetectable at $4 \mu \mathrm{M}$.

\section{Epigenetic effects on ER- $\alpha$ and EGFR expression in MDA-231 cells}

MDA-231 cells were treated with or without CAPE as well as with a control HDAC inhibitor, LBH 589 and then ER- $\alpha$ expression detected by immunofluorescence (receptor protein) and RT-PCR (gene). Immunofluorescence was performed and ER- $\alpha$ expression detected using ER- $\alpha$ primary antibody and a DAPI nuclear stain. While MDA-
231 cells do not express ER- $\alpha$ at $40 \mu \mathrm{M}$ CAPE, ER- $\alpha$ receptor protein expression was markedly turned on, even to a level greater than that seen in the control LBH 589 (Figure 5A, top panel). Treatment with CAPE exposure resulted in the re-expression of a previously silenced ER-a gene in MDA- 231 TNBC cells, which is comparable to the established histone deacetylase inhibitor LBH 589 (Figure 5A, bottom panel) as seen by PCR. EGFR is overexpressed in MDA -231 cells and there is a known significant inverse association between expression levels of estrogen receptor $\alpha$ and EGFR in human breast cancer [32]. CAPE and propolis treatment result in a decrease of EGFR expression in MDA-231 cells, which was again more potent using propolis after normalizing for CAPE content (Figure 5B).

\section{Effects on p-Her2 expression in SKBR3 cells}

Following treatment of SKBR3 cells with CAPE or propolis for 24 $\mathrm{h}$, protein lysates were subjected to western blotting. Immunoblotting with anti-phoshorylated Her2 (p-Her2) antibody demonstrated a concentration dependent decrease in p-Her2 by both CAPE and propolis and similar to previous results, propolis, when normalized for CAPE content, effects this decline in p-Her2 at significantly lower 
Citation: Omene C, Kalac M, Wu J, Marchi E, Frenkel K, et al. (2013) Propolis and its Active Component, Caffeic Acid Phenethyl Ester (CAPE), Modulate Breast Cancer Therapeutic Targets via an Epigenetically Mediated Mechanism of Action. J Cancer Sci Ther 5: 334-342. doi:10.4172/1948-5956.1000224

A.

Immunofluorescence
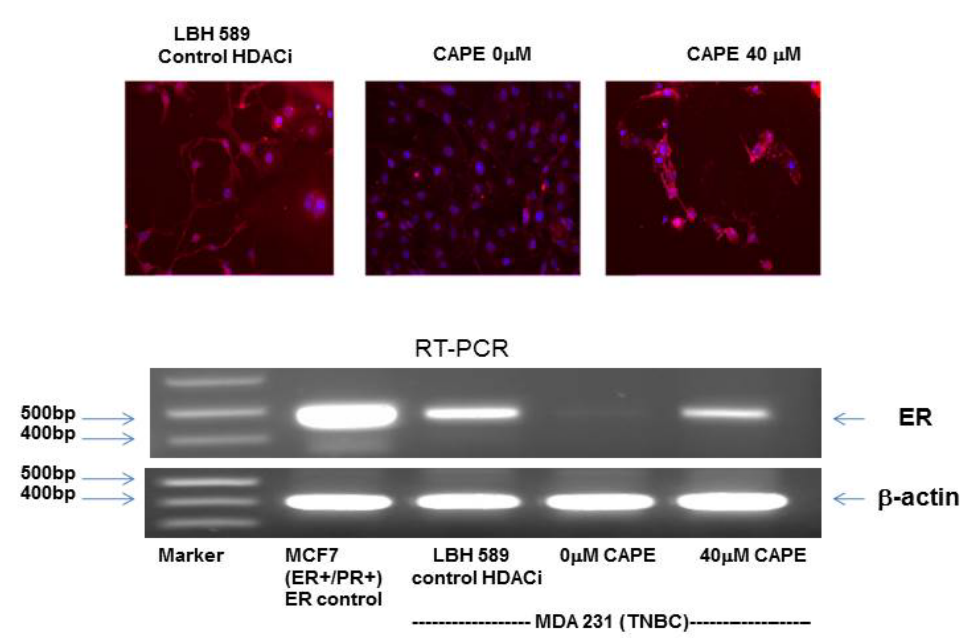

B.

Propolis $^{*}$

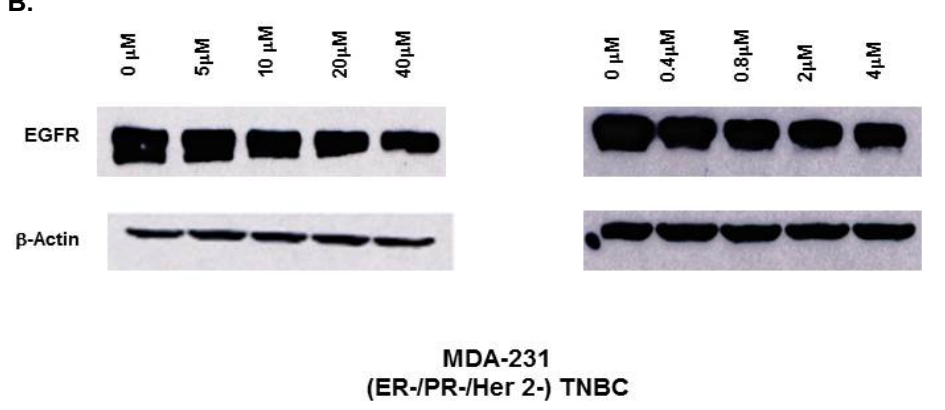

Figure 5: Propolis/CAPE epigenetically modulates ER- $\alpha$ and EGFR in MDA-231 (TNBC) cells: MDA-231 cells were treated with and without CAPE or with control LBH 589. ER- $\alpha$ is upregulated in the presence of CAPE as seen by immunofluorescence (top panel) and RT-PCR (bottom panel) (Figure 5A). CAPE and propolis (normalized for CAPE content) decrease EGFR protein expression in a concentration-dependent manner in MDA-231 cells (Figure 5B).

CAPE

A.

A.

p-Her 2

$\beta$-Actin

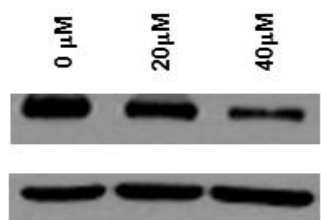

Propolis $^{*}$

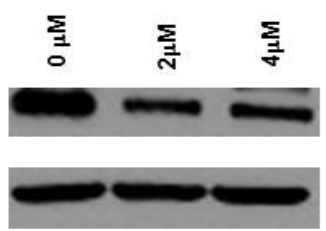

Propolis*

B.

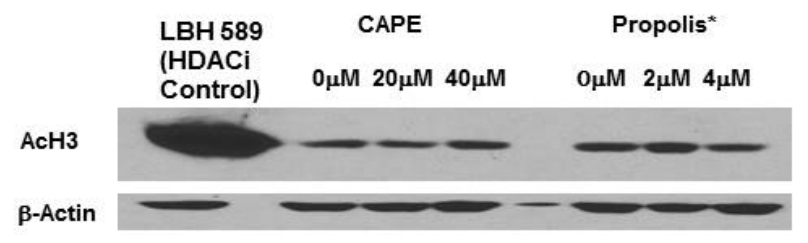

Figure 6: Propolis/CAPE decreases p-Her2 in SKBR3 cells: SKBR3 cells were treated with CAPE or Propolis for $24 \mathrm{~h}$ and western blotting performed (Figure 6A). There is a concentration-dependent decrease in p-Her2 protein expression by both CAPE and propolis (normalized for CAPE content). No hyperacetylation of histone protein was observed in the SKBR3 cell line with the antibody used (Figure 6B). 
Citation: Omene C, Kalac M, Wu J, Marchi E, Frenkel K, et al. (2013) Propolis and its Active Component, Caffeic Acid Phenethyl Ester (CAPE), Modulate Breast Cancer Therapeutic Targets via an Epigenetically Mediated Mechanism of Action. J Cancer Sci Ther 5: 334-342. doi:10.4172/1948-5956.1000224

levels than CAPE alone (Figure 6A). No hyper-acetylation of histone proteins was observed in the SKBR3 cell line with the antibodies used (Figure 6B).

\section{Discussion}

There are different types of propolis based on its geographic origin, including North America, Europe, New Zealand, Brazil and China. While propolis from these different continents is made the same way, differences in the botanicals indigenous to these areas leads to slight differences in the relative concentrations of different chemicals in propolis, including compounds such as flavonoids, phenolic acids, and their esters, terpenoids, steroids and amino-acids [6].

We have previously described that CAPE, the major active component of propolis, induces a diversity of anti-tumor effects in ER+ and ER- breast cancer $[25,26]$. Here, we compared propolis with CAPE alone to determine whether CAPE's effects were intact in the natural product. We show that the cytotoxic effects of CAPE are intact in the natural product, propolis in the different breast cancer cell lines and we show for the first time the inhibitory effects on the Her 2 over expressing breast cancer cell line SKBR3. Moreover, the cytotoxic effects are more potent with propolis when normalized for CAPE content by HPLC (Figure 2). We previously demonstrated that CAPE inhibits growth of breast cancer cells and breast cancer stem cells, induces cell cycle arrest and apoptosis, and suppresses angiogenesis. Gene arrays showed that CAPE causes extensive changes in gene expression in both ER+ and ER- types of breast cancer cells including the inhibition of NF- $\mathrm{kB}$ $[25,26]$.

These findings are reminiscent of the pleiotropic effects of histone deacetylases inhibitors (HDACi) like vorinostat, aliphatic acids and depsipeptide in models of both epithelial and hematopoietic origin. Inhibitors of HDAC enzymes alter patterns of gene expression, induce cellular differentiation, and promote cell cycle arrest and apoptosis $[33,34]$. They include, the hydroxamic class of HDACi like Panobinostat (LBH 589) an experimental drug in clinical trials, which acts as a non-selective HDAC inhibitor [35,36], while Vorinostat (SAHA, suberoylanilidehydroxamic acid) is a HDAC inhibitor that binds directly to the catalytic site of the enzyme thereby blocking substrate access, and it inhibits class I and class II HDACs at nanomolar concentrations (IC50 <86 nM) [37,38]. We hypothesized that CAPE, which is structurally similar to the hydroxamic acid class of HDAC inhibitors (Figure 1), could mediate its effects on breast cancer through epigenetic modifications and thus, could modulate breast cancer therapeutic targets such as ER, PR, and Her2/neu.

We demonstrated exposure to CAPE and propolis (normalized for CAPE content) leads to the accumulation of acetylated histone 3 proteins (Ac H3)in MCF-7 (ER+/PR+) and MDA-231 (triple negative breast cancer (TNBC, ER-/PR-/Her2-) breast cancer cell lines (Figure 3). The international patent application on this finding was published in January, 2013 by our group, Omene C, O'Connor OA and Frenkel K. The ability to repress cyclin D1 and to increase the acetylation of histone proteins is indicative of histone deacetylase inhibitor activity [39]. We have previously shown that CAPE decreases cyclin D1 expression by 7 fold [25]. Together, this suggests that CAPE's effects may lie in part in its ability to inhibit histone deacetylases directly or indirectly, thus making CAPE and propolis a naturally occurring epigenetic therapeutic agent (Figure 3). We established that the epigenetic effects of CAPE are recapitulated in the natural product, by determining the concentration of CAPE in propolis by HPLC. The data provided show that when normalized for the concentration of CAPE in propolis, the HDAC inhibitory effects of the natural product, propolis, are in fact markedly superior to that seen when CAPE is used as a single agent. Interestingly, the aliphatic structure of CAPE is within the expected structural class of chemicals known to possess this unusual activity. Alternatively, this may also be due to the presence of caffeic acid, the hydrolyzed product from CAPE metabolism, which is present alongside CAPE in propolis, leading to enhanced HDAC inhibitory effects.

Two compounds, NBM-HD-1 and NBM-HD-3 have been recently derived from the semi-synthesis of propolin $\mathrm{G}$, isolated from Taiwanese green propolis (TGP), and shown to act as an HDACi $[40,41]$. Similarly, the flavonoid Chrysin, found in the Chinese propolis has been demonstrated to be an HDAC inhibitor [42]. Here we show for the first time that CAPE has HDAC inhibitory properties that are even more potent when normalized by HPLC in its natural form in the North American propolis. In an effort to interrogate this mechanism of action, we explored the effect of CAPE and Propolis in different breast cancer pathways. The results reveal that CAPE and propolis modulate therapeutic determinants of breast cancer, including ER, PR, Her2 neu, and EGFR (erbB1/Her1)

Estrogen plays a key role in normal breast development. In breast cancer cells expressing estrogen receptors (ER), estrogen has potent proliferative effects and also affects differentiation and survival [43]. Inhibition of ER and PR (an estrogen response gene) is a mainstay of therapy in patients with ER and/or PR positive breast cancer using selective estrogen receptor modulators, such as tamoxifen, aromatase inhibitors and pure ER antagonists, like fulvestrant [44]. Blocking estrogen activity represents an effective treatment for most ER+ metastatic breast cancer patients, however acquired drug resistance to aromatase inhibitors leads to disease progression, ultimately requiring less effective, more toxic chemotherapies [45]. Delaying resistance and disease progression represents a significant unmet need that could prolong survival while decreasing health care costs associated with chemotherapy and hospitalization.

We demonstrate that ER+MCF7 cells treated with CAPE or propolis downregulated both ER and PR, where the effects seen with Propolis were more than that seen with CAPE alone. This consistent pattern is probably attributed to the fact that propolis contains a variety of other components which may complement the epigenetic effects of CAPE alone (Figure 4). When combined with exemestane, entinostat, an HDACi in Phase 2 clinical trials, provided survival benefit for postmenopausal women with estrogen-receptor positive metastatic breast cancer [46,47]. With a median follow-up of 18 months, overall survival was significantly longer with exemestane plus entinostat than with exemestane plus placebo (26.94 versus 20.33 months, respectively). In the subset of entinostat patients exhibiting histone hyperacetylation, median progression free survival (PFS) increased to over six months [47]. This provides support for future study of CAPE in ER+ breast cancer and is particularly interesting given that we are able to show hyperacetylation of histone proteins in a human volunteer after oral ingestion with CAPE-containing propolis (Figure 3), thus this can readily be used as a biomarker for efficacy in a clinical trial.

The reactivation of a functional estrogen receptor in ER negative or triple negative breast cancer cells by an $\mathrm{HDACi}$, including the hydroxamic acid LBH 589 has been established in previous publications $[48,49]$. Given the increased mortality rates and paucity of therapeutic options for patients with ER negative breast cancers, novel agents that could reactivate ER and allow for the use of endocrine therapy to target the ER in these patients would be a valuable therapeutic approach. We exhibit here that CAPE exposure epigenetically results in the re- 
Citation: Omene C, Kalac M, Wu J, Marchi E, Frenkel K, et al. (2013) Propolis and its Active Component, Caffeic Acid Phenethyl Ester (CAPE), Modulate Breast Cancer Therapeutic Targets via an Epigenetically Mediated Mechanism of Action. J Cancer Sci Ther 5: 334-342. doi:10.4172/1948-5956.1000224

expression of the previously silenced ER gene and protein in MDA231 TNBC cells comparable to more established HDAC inhibitors like LBH 589 as shown by immunofluorescence (Figure 5A, top panel) and RT-PCR (Figure 5A, bottom panel). A previous study showed CAPE decreases ER expression rather than induction in MDA 231 cells which is opposite to our findings [50]. This is an unexpected observation due to the fact that MDA-231 cells, which are ER- should not express ER at all. We show in Figure 5B using PCR that our MDA-231 cell line at the gene expression level does not express ER. This is rather in agreement with other published data including the pertinent paper by Zhou Q et al. [48], which shows that their MDA-231 cell line clearly does not express ER in any of the control (untreated) cell lanes. We can only speculate that perhaps there may have been a contamination of their MDA231 cell line by MCF-7 (ER+) which they show as well in that paper or perhaps subtle changes in culture conditions or variation in MDA231 cells accounts for the findings with the MDA-231 cells reported in their paper. Several studies have suggested that over expression of EGFR is a marker for poor prognosis in breast cancer patients that is significantly correlated with the loss of endocrine sensitivity [51-53]. There is evidence that the re-expression of ER protein by a clinically relevant HDAC inhibitor like SAHA, is coupled with loss of EGFR in ER-negative human breast cancer cells [54]. We demonstrate that treatment by CAPE, results in a decrease of EGFR in a concentrationdependent manner and that this inhibitory effect of CAPE is more potent when using propolis (Figure $5 \mathrm{~B}$ ).

Approximately $25 \%$ of breast cancers exhibit amplification and over-expression of her2/neu oncogene, which encodes for Her2, a member of the family of epidermal growth factor receptor tyrosine kinases [55,56]. Her2 over expression, similar to ER negative breast cancer, has been associated with an inferior prognosis in breast cancer. However, the existence of Her2 targeted therapy like the recombinant, humanized, monoclonal anti-Her2 antibody, trastuzumab (Herceptin), has exhibited significant clinical efficacy against breast cancer $[57,58]$, and has overcome some of the adverse prognostic features of Her2 over-expression. Unfortunately, resistance to trastuzumab, administered alone or in combination with chemotherapeutic agents is common $[59,60]$. The HDAC Inhibitor entinostat induces apoptosis in Her2 overexpressing breast cancer cells and causes a decrease in phoshorylated Her2 [61]. Similarly, the HDAC inhibitor, SAHA possesses activity against Her2 over-expressing human breast cancer cells with associated decrease in Her2 [62]. We show that CAPE and propolis are cytotoxic to Her2 over expressing breast cancer cells and similarly to other HDACi causes a decrease in phoshorylated Her2 in the Her2 over expressing cell line SKBR3 (Figure 6). We were not able to show accumulation of acetylated histone proteins in the SKBR3 cell line perhaps either due to the antibody used or that in this cell line, a selective HDAC is being inhibited which does not acetylate the histone 3 protein tested.

\section{Conclusion}

In conclusion, we demonstrate here for the first time that CAPE causes the accumulation of acetylated histone proteins suggesting that it has HDAC inhibitory properties, and this mechanism is intact and potent in the natural product propolis. This suggests that its anticancer properties is in part due to its effects on HDACs and provides support for the use of CAPE as a therapeutic agent in breast cancer. Furthermore, the epigenetic effects result in a pharmacomodulation of all the well known breast cancer therapeutic targets. More particularly, the data presented herein show that in ER+ BC cell lines, CAPE, either alone or present in ethanolic propolis extract, induces decreases in hormone receptors, estrogen receptor (ER) and progesterone receptor (PR), suggesting that this decrease in expression could lead to antihormonal effects in hormonal therapy refractory cells of estrogen receptor positive patients.

The re-expression of ER- $\alpha$ receptor and gene in triple-negative breast cancer cells following treatment with CAPE could render TNBC patients susceptible to anti-estrogen therapy, when used in combination with hormonal therapy, in either the adjuvant or metastatic setting as well as for chemoprevention. The decreases in over-expression of EGFR in TNBC and phosphorylated Her2 in Her2 over expressing BC following treatment with propolis or CAPE suggest that these could be excellent candidates for targeted therapy against these proteins in patients who have TNBC or in Her2 positive patients who have progressed on anti-Her2 therapy.

Finally, our published work revealed that CAPE inhibits expression of the mdr-1 [25] gene known to confer resistance to chemotherapeutic drugs in cancer cells, which could account for the strong inhibition of growth and cell cycle arrest by a concurrent treatment of CAPE and Taxol in vitro and in vivo when each is used at suboptimal doses (manuscript in preparation). This decrease in mdr genes/proteins coupled with its inhibitory properties on HDACs, could allow CAPE to be used in combination with standard chemotherapeutic drugs as well.

These results of CAPE are present in the naturopathic formulation of propolis, a widely available natural substance with an extended safety record, making it a naturally-occurring and readily available epigenetic agent with great potential in breast cancer and oncology in general The ability to link the biological effects of a naturopathic remedy to the pharmacologic effects seen with an exciting class of drugs in the treatment of cancer opens the door to a host of new therapeutic opportunities for patients with limited options like ER+ refractory metastatic breast cancer or TNBC. Ongoing research should further delineate the mechanism(s) of CAPE as an HDAC inhibitor, either directly or indirectly, in the different subtypes of breast cancer.

\section{Acknowledgements}

We thank Dr. Mary Helen Barcellos-Hoff for her critical review of this manuscript.

\section{Financial Support}

This work was supported in part by the following grants:

Dr. Coral Omene: K08CA172722 (NIH/NCI), the content is solely the responsibility of the authors and does not necessarily represent the official views of the National Institutes of Health. (NIEHS).

Dr. KrystynaFrenkel: BCTR0600476 (Komen for the Cure) and ES00260 Dr. Owen A. O'Connor: Leukemia \& Lymphoma Society grant LLS 7017-09.

\section{Conflict of Interest}

The authors do not have any conflicts of interest to disclose.

\section{References}

1. Boon H, Brown JB, Gavin A, Kennard MA, Stewart M (1999) Breast cancer survivors' perceptions of complementary/alternative medicine (CAM): making the decision to use or not to use. Qual Health Res 9: 639-653.

2. Crocetti E, Crotti N, Feltrin A, Ponton P, Geddes M, et al. (1998) The use of complementary therapies by breast cancer patients attending conventional treatment. Eur J Cancer 34: 324-328.

3. Sparber A, Bauer L, Curt G, Eisenberg D, Levin T, et al. (2000) Use of complementary medicine by adult patients participating in cancer clinical trials. Oncol Nurs Forum 27: 623-630. 
Citation: Omene C, Kalac M, Wu J, Marchi E, Frenkel K, et al. (2013) Propolis and its Active Component, Caffeic Acid Phenethyl Ester (CAPE), Modulate Breast Cancer Therapeutic Targets via an Epigenetically Mediated Mechanism of Action. J Cancer Sci Ther 5: 334-342. doi:10.4172/1948-5956.1000224

4. Richardson MA, Sanders T, Palmer JL, Greisinger A, Singletary SE (2000) Complementary/alternative medicine use in a comprehensive cancer center and the implications for oncology. J Clin Oncol 18: 2505-2514

5. Morris KT, Johnson N, Homer L, Walts D (2000) A comparison of complementary therapy use between breast cancer patients and patients with other primary tumor sites. Am J Surg 179: 407-411.

6. Burdock GA (1998) Review of the biological properties and toxicity of bee propolis (propolis). Food Chem Toxicol 36: 347-363.

7. Lotfy M, Badra G, Burham W, Alenzi FQ (2006) Combined use of honey, bee propolis and myrrh in healing a deep, infected wound in a patient with diabetes mellitus. Br J Biomed Sci 63: 171-173.

8. Castaldo S, Capasso F (2002) Propolis, an old remedy used in modern medicine. Fitoterapia 73 Suppl 1: S1-6.

9. Ansorge S, Reinhold D, Lendeckel U (2003) Propolis and some of its constituents down-regulate DNA synthesis and inflammatory cytokine production but induce TGF-beta1 production of human immune cells. Z Naturforsch C 58: 580-589.

10. Son S, Lewis BA (2002) Free radical scavenging and antioxidative activity of caffeic acid amide and ester analogues: structure-activity relationship. J Agric Food Chem 50: 468-472.

11. Koltuksuz U, MutuÅŸ HM, Kutlu R, Ozyurt H, Cetin S, et al. (2001) Effects of caffeic acid phenethyl ester and epidermal growth factor on the development of caustic esophageal stricture in rats. J Pediatr Surg 36: 1504-1509.

12. Michaluart $P$, Masferrer JL, Carothers AM, Subbaramaiah K, Zweifel BS, et al. (1999) Inhibitory effects of caffeic acid phenethyl ester on the activity and expression of cyclooxygenase-2 in human oral epithelial cells and in a rat model of inflammation. Cancer Res 59: 2347-2352.

13. Borrelli F, Izzo AA, Di Carlo G, Maffia P, Russo A, et al. (2002) Effect of a propolis extract and caffeic acid phenethyl ester on formation of aberrant crypt foci and tumors in the rat colon. Fitoterapia 73 Suppl 1: S38-43.

14. Frenkel K, Wei H, Bhimani R, Ye J, Zadunaisky JA, et al. (1993) Inhibition of tumor promoter-mediated processes in mouse skin and bovine lens by caffeic acid phenethyl ester. Cancer Res 53: 1255-1261.

15. Huang MT, Ma W, Yen P, Xie JG, Han J, et al. (1996) Inhibitory effects of caffeic acid phenethyl ester (CAPE) on 12-O-tetradecanoylphorbol-13-acetateinduced tumor promotion in mouse skin and the synthesis of DNA, RNA and protein in HeLa cells. Carcinogenesis 17: 761-765.

16. Yang C, Wu J, Zhang R, Zhang P, Eckard J, et al. (2005) Caffeic acid phenethy ester (CAPE) prevents transformation of human cells by arsenite (As) and suppresses growth of As-transformed cells. Toxicology 213: 81-96.

17. Xiang D, Wang D, He Y, Xie J, Zhong Z, et al. (2006) Caffeic acid phenethy ester induces growth arrest and apoptosis of colon cancer cells via the betacatenin/T-cell factor signaling. Anticancer Drugs 17: 753-762.

18. Chen MF, Wu CT, Chen YJ, Keng PC, Chen WC (2004) Cell killing and radiosensitization by caffeic acid phenethyl ester (CAPE) in lung cancer cells. J Radiat Res 45: 253-260.

19. Kudugunti SK, Vad NM, Ekogbo E, Moridani MY (2011) Efficacy of caffeic acid phenethyl ester (CAPE) in skin B16-F0 melanoma tumor bearing C57BL/6 mice. Invest New Drugs 29: 52-62.

20. Kuo HC, Kuo WH, Lee YJ, Lin WL, Chou FP, et al. (2006) Inhibitory effect of caffeic acid phenethyl ester on the growth of $\mathrm{C} 6$ glioma cells in vitro and in vivo. Cancer Lett 234: 199-208.

21. Chen MJ, Chang WH, Lin CC, Liu CY, Wang TE, et al. (2008) Caffeic Acid Phenethyl Ester Induces Apoptosis of Human Pancreatic Cancer Cells Involving Caspase and Mitochondrial Dysfunction. Pancreatology 8: 566-576.

22. Wu CS, Chen MF, Lee IL, Tung SY (2007) Predictive role of nuclear factorkappaB activity in gastric cancer: a promising adjuvant approach with caffeic acid phenethyl ester. J Clin Gastroenterol 41: 894-900.

23. Onori P, DeMorrow S, Gaudio E, Franchitto A, Mancinelli R, et al. (2009) Caffeic acid phenethyl ester decreases cholangiocarcinoma growth by inhibition of NFkappaB and induction of apoptosis. Int J Cancer 125: 565-576.

24. Lee K, Kang N, Kim J, Lee K, Lee D, et al. (2008) Caffeic acid phenethyl ester inhibits invasion and expression of matrix metalloproteinase in SK-Hep1 human hepatocellular carcinoma cells by targeting nuclear factor kappa B. Genes Nutr 2: 319-322.

25. Wu J, Omene C, Karkoszka J, Bosland M, Eckard J, et al. (2011) Caffeic acid phenethyl ester (CAPE), derived from a honeybee product propolis, exhibits a diversity of anti-tumor effects in pre-clinical models of human breast cancer. Cancer Lett 308: 43-53.

26. Omene CO, Wu J, Frenkel K (2012) Caffeic Acid Phenethyl Ester (CAPE) derived from propolis, a honeybee product, inhibits growth of breast cancer stem cells. Invest New Drugs 30: 1279-1288.

27. Song SH, Han SW, Bang YJ (2011) Epigenetic-based therapies in cancer: progress to date. Drugs 71: 2391-2403.

28. Yoo CB, Jones PA (2006) Epigenetic therapy of cancer: past, present and future. Nat Rev Drug Discov 5: 37-50.

29. O'Connor OA, Heaney ML, Schwartz L, Richardson S, Willim R, et al. (2006) Clinical Experience With Intravenous and Oral Formulations of the Nove Histone Deacetylase Inhibitor SuberoylanilideHydroxamic Acid in Patients With Advanced Hematologic Malignancies. J Clin Oncol 24: 166-173.

30. Kelly WK, O'Connor OA, Krug LM, Chiao JH, Heaney M, et al. (2005) Phase study of an oral histone deacetylase inhibitor, suberoylanilide hydroxamic acid, in patients with advanced cancer. J Clin Oncol 23: 3923-3931.

31. Wagner JM, Hackanson B, Lübbert M, Jung M (2010) Histone deacetylase (HDAC) inhibitors in recent clinical trials for cancer therapy. Clin Epigenetics 1: 117-136.

32. Davidson NE, Gelmann EP, Lippman ME, Dickson RB (1987) Epidermal growth factor receptor gene expression in estrogen receptor-positive and negative human breast cancer cell lines. Mol Endocrinol 1: 216-223.

33. Marks PA, Richon VM, Rifkind RA (2000) Histone deacetylase inhibitors: inducers of differentiation or apoptosis of transformed cells. J Natl Cancer Inst 92: 1210-1216.

34. Mitsiades CS, Mitsiades NS, McMullan CJ, Poulaki V, Shringarpure R, et al (2004) Transcriptional signature of histone deacetylase inhibition in multiple myeloma: Biological and clinical implications. Proc Natl Acad Sci U S A 101 540-545.

35. Maiso P, Carvajal-Vergara X, Ocio EM, López-Pérez R, Mateo G, et al. (2006) The histone deacetylase inhibitor LBH589 is a potent antimyeloma agent that overcomes drug resistance. Cancer Res 66: 5781-5789.

36. Lane AA, Chabner BA (2009) Histone deacetylase inhibitors in cancer therapy. $\mathrm{J}$ Clin Oncol 27: 5459-5468.

37. Marks PA, Breslow R (2007) Dimethyl sulfoxide to vorinostat: development of this histone deacetylase inhibitor as an anticancer drug. Nat Biotechnol 25 84-90.

38. Tan J, Cang S, Ma Y, Petrillo RL, Liu D (2010) Novel histone deacetylase inhibitors in clinical trials as anti-cancer agents. $\mathrm{J}$ Hematol Oncol 3: 5.

39. Sakajiri S, Kumagai T, Kawamata N, Saitoh T, Said JW, et al. (2005) Histone deacetylase inhibitors profoundly decrease proliferation of human lymphoid cancer cell lines. Exp Hematol 33: 53-61.

40. Huang WJ, Lin CW, Lee CY, Chi LL, Chao YC, et al. (2011) NBM-HD-3, a novel histone deacetylase inhibitor with anticancer activity through modulation of PTEN and AKT in brain cancer cells. J Ethnopharmacol 136: 156-167.

41. Huang WJ, Liang YC, Chuang SE, Chi LL, Lee CY, et al. (2012) NBM-HD-1: A Novel Histone Deacetylase Inhibitor with Anticancer Activity. Evid Based Complement Alternat Med 2012: 781417.

42. Sun LP, Chen AL, Hung HC, Chien YH, Huang JS, et al. (2012) Chrysin: a histone deacetylase 8 inhibitor with anticancer activity and a suitable candidate for the standardization of Chinese propolis. J Agric Food Chem 60: 1174811758.

43. Zhou Q, Davidson NE (2006) Silencing estrogen receptor alpha in breast cancer cells. Cancer Biol Ther 5: 848-849.

44. Davidson NE (2000) Combined endocrine therapy for breast cancer--new life for an old idea? J Natl Cancer Inst 92: 859-860.

45. Hurvitz SA, Pietras RJ (2008) Rational management of endocrine resistance in breast cancer: a comprehensive review of estrogen receptor biology, treatment options, and future directions. Cancer 113: 2385-2397.

46. Wardley A, Stein R, McCaffrey J, Crown J, Malik Z, et al. (2010) Phase II data for entinostat, a class 1 selective histone deacetylase inhibitor, in patients whose breast cancer is progressing on aromatase inhibitor therapy. $\mathrm{J}$ ClinOncol 28: $15 \mathrm{~s}$. 
Citation: Omene C, Kalac M, Wu J, Marchi E, Frenkel K, et al. (2013) Propolis and its Active Component, Caffeic Acid Phenethyl Ester (CAPE), Modulate Breast Cancer Therapeutic Targets via an Epigenetically Mediated Mechanism of Action. J Cancer Sci Ther 5: 334-342. doi:10.4172/1948-5956.1000224

47. Yardley DA I-KR, Klein PM (2011) PD01-04: Entinostat, a Novel Histone Deacetylase Inhibitor, Added to Exemestane Improves PFS in Advanced Breast Cancer in a Randomized, Phase II, Double-Blind Study, Cancer Res 71: 5472.

48. Zhou Q, Atadja P, Davidson NE (2007) Histone deacetylase inhibitor LBH589 reactivates silenced estrogen receptor alpha $(E R)$ gene expression without loss of DNA hypermethylation. Cancer Biol Ther 6: 64-69.

49. Yang X, Phillips DL, Ferguson AT, Nelson WG, Herman JG, et al. (2001) Synergistic Activation of Functional Estrogen Receptor (ER)-a by DNA Methyltransferase and Histone Deacetylase Inhibition in Human ER-a-negative Breast Cancer Cells. Cancer Res 61: 7025-7029.

50. Jung BI, Kim MS, Kim HA, Kim D, Yang J, et al. (2010) Caffeic acid phenethyl ester, a component of beehive propolis, is a novel selective estrogen receptor modulator. Phytother Res 24: 295-300.

51. Nicholson RI, McClelland RA, Gee JM, Manning DL, Cannon P, et al. (1994) Epidermal growth factor receptor expression in breast cancer: association with response to endocrine therapy. Breast Cancer Res Treat 29: 117-125.

52. Nicholson S, Wright C, Sainsbury JR, Halcrow P, Kelly P, et al. (1990) Epidermal growth factor receptor (EGFr) as a marker for poor prognosis in node-negative breast cancer patients: neu and tamoxifen failure. J Steroid Biochem Mol Biol 37: 811-814

53. Knowlden JM, Hutcheson IR, Jones HE, Madden T, Gee JMW, et al. (2003) Elevated Levels of Epidermal Growth Factor Receptor/c-erbB2 Heterodimers Mediate an Autocrine Growth Regulatory Pathway in Tamoxifen-Resistant MCF-7 Cells. Endocrinology 144: 1032-1044.

54. Zhou Q, Shaw PG, Davidson NE (2009) Inhibition of histone deacetylase suppresses EGF signaling pathways by destabilizing EGFR mRNA in ERnegative human breast cancer cells. Breast Cancer Res Treat 117: 443-451.

55. Harari D, Yarden Y (2000) Molecular mechanisms underlying ErbB2/HER2 action in breast cancer. Oncogene 19: 6102-6114.

56. Hynes NE, Lane HA (2005) ERBB receptors and cancer: the complexity of targeted inhibitors. Nat Rev Cancer 5: 341-354.

57. Cobleigh MA, Vogel CL, Tripathy D, Robert NJ, Scholl S, et al. (1999) Multinational Study of the Efficacy and Safety of Humanized Anti-HER2 Monoclonal Antibody in Women Who Have HER2-Overexpressing Metastatic Breast Cancer That Has Progressed After Chemotherapy for Metastatic Disease. J Clin Oncol 17: 2639.

58. Baselga J, Norton L, Albanell J, Kim YM, Mendelsohn J (1998) Recombinant Humanized Anti-HER2 Antibody (Herceptin ${ }^{\mathrm{TM}}$ ) Enhances the Antitumor Activity of Paclitaxel and Doxorubicin against HER2/neu Overexpressing Human Breast Cancer Xenografts. Cancer Res 58: 2825-2831.

59. Lu Y, Zi X, Zhao Y, Mascarenhas D, Pollak M (2001) Insulin-like growth factor-I receptor signaling and resistance to trastuzumab (Herceptin). J Natl Cancer Inst 93: 1852-1857.

60. Nagata Y, Lan KH, Zhou X, Tan M, Esteva FJ, et al. (2004) PTEN activation contributes to tumor inhibition by trastuzumab, and loss of PTEN predicts trastuzumab resistance in patients. Cancer Cell 6: 117-127.

61. Huang X, Gao L, Wang S, Lee CK, Ordentlich P, et al. (2009) HDAC inhibitor SNDX-275 induces apoptosis in erbB2-overexpressing breast cancer cells via down-regulation of erbB3 expression. Cancer Res 69: 8403-8411.

62. Bali P, Pranpat M, Swaby R, Fiskus W, Yamaguchi H, et al. (2005) Activity of suberoylanilide hydroxamic Acid against human breast cancer cells with amplification of her-2. Clin Cancer Res 11: 6382-6389. 